\title{
HEPATOCARCINOGENESIS AND CERAMIDE/CHOLESTEROL \\ METABOLISM
}

Albert Morales ${ }^{1}$, Montserrat Marí ${ }^{1}$, Carmen García-Ruiz ${ }^{1}$, Anna Colell ${ }^{1}$ and Jose C. Fernández-Checa ${ }^{1,2}$

\footnotetext{
${ }^{1}$ Department of Cell Death and Proliferation, IIBB-CSIC, and IDIBAPS, Liver UnitHospital Clinic, Centro Esther Koplowitz , 08036-Barcelona, Spain; ${ }^{2}$ Research Center for Alcoholic Liver and Pancreatic Diseases, Keck School of Medicine of the University of Southern California, Los Angeles, CA, USA.
}

Grant Support: The work was supported by CIBEREHD and grants PI10/02114 and PI09/0056 (Instituto de Salud Carlos III), SAF2008-02199, SAF2009-11417, SAF201015760 (Plan Nacional de I+D), Spain; and P50-AA-11999 (Research Center for Liver and Pancreatic Diseases, NIAAA/NIH).

Correspondence to: Albert Morales, amorales@clinic.ub.es, or José C. FernandezCheca, checa229@yahoo.com. Address: Centro Esther Koplowitz, C/ Rosselló 151, 08036-Barcelona, Spain. 


\begin{abstract}
Sphingolipids (SLs) and cholesterol are critical structural components of membrane bilayers. Although recent evidence has revealed an emerging role of both lipids in signaling pathways, their contribution to cancer development and treatment has been largely overlooked. Sphingolipids comprise a family of bioactive lipids with divergent roles in numerous cellular processes. In particular, ceramide is the prototype of SLs and identified as a cell death effector whose levels increase in response to apoptotic stimuli such as ionizing radiation or chemotherapy. In the liver, ceramide/cholesterol accumulation contributes to a wide range of pathologies, including the transition from steatosis to steatohepatitis, which can further progress to cirrhosis and hepatocellular carcinoma (HCC). Moreover, different studies have shown that either pharmacologic ceramide accumulation or systemic intravenous administration of liposomal ceramide is an effective approach against HCC. In addition, mitochondrial cholesterol trafficking has emerged as a novel factor regulating cell death pathways and HCC tumor growth and chemoresistance. Due to the poor efficacy of current HCC treatments, understanding of the role of ceramide/cholesterol in HCC may open up novel avenues for therapy. Here we describe recent evidence indicating that ceramide-generating agents and/or pharmacological targeting of sphingolipid/cholesterol metabolism, alone or in combination with other chemotherapeutic compounds, may be a promising strategy in HCC management.
\end{abstract}




\section{INTRODUCTION}

Bioactive sphingolipids (SLs) comprise a family of lipids with divergent roles in numerous cellular processes. For instance, ceramide, sphingosine-1-phosphate (S1P) or GD3 ganglioside, exert antagonizing roles in diverse cellular functions such as growth arrest, cell proliferation, or apoptosis $[1,2,3,4,5]$. Ceramide is the prototype of SLs and has been the subject of intense scrutiny and research due to its role in controlling signaling pathways leading to cell death in response to apoptotic stimuli (e.g. stress, death ligands, radiation or chemotherapy) $[5,6,7]$, as well as in the organization of specific signaling domains of plasma membrane termed ceramide-rich platforms [8]. Cells generate ceramide by different pathways, most predominantly from the de novo synthesis from L-serine and palmitoyl-CoA in the ER that requires the concerted action of several enzymes. While this pathway is slow and sustained in time, there is another fashion whereby cells generate ceramide quickly, and often, transiently, mainly due to the breakdown of sphingomyelin upon activation of sphingomyelinases (SMases). Once produced, ceramide may target different signaling pathways involved in cell death, thus underlying its proapoptotic function $[1,2]$ or can be metabolized to other derivatives with divergent functions. While the ceramidase/sphingosine kinase axis generates antiapoptotic derivatives (e.g. S1P), the addition of carbohydrates and sialic acid residues to ceramide generates complex sphingolipids, such as gangliosides, which transmit the proapoptotic function of ceramide depending on its intracellular distribution. The synthesis of glucosylceramide to complex glycosphingolipids requires the transfer of ceramide from the ER to the Golgi by specific proteins (e.g. CERT) that regulate ceramide homeostasis. Since ceramide and gangliosides (e.g. GD3) are proapoptotic, the loss or gain of function of CERT may represent another mechanism to regulate cell death and cancer development [9]. 
Moreover, cholesterol is an integral component of cellular membranes that plays an essential role in maintaining their integrity and function. Although cholesterol homeostasis has been the subject of intense research in the context of cardiovascular diseases, there is a growing body of evidence pointing to a critical role of cholesterol in liver physiopathology, particularly emerging as a key player in chronic liver diseases, including steatohepatitis, a prevalent form of liver disease characterized by steatosis, inflammation, oxidative stress, hepatocellular death, and fibrosis, which can further progress to more advanced states such as cirrhosis and hepatocellular carcinoma (HCC). $\mathrm{HCC}$ is one of the main causes of cancer-related death that exhibits high resistance to current therapy. Alterations in cholesterol metabolism and intracellular trafficking have been disclosed as critical factors in HCC biology and therapy, and hence may constitute novel targets to improve the current treatment armamentarium for HCC. In the present review, we will briefly cover emerging new aspects of the metabolism of ceramide and cholesterol in HCC, focusing on novel developments suggesting that targeting these lipids may be of relevance as a new therapeutic approach in HCC.

\section{Ceramide formation from de novo synthesis.}

SLs and their metabolites are major components of biological membranes that in addition to the key structural role also act as signaling molecules. This functional dichotomy is determined by their structural diversity, as SLs encompass a large group of lipids, including sphingosines, ceramides, sphingomyelin, and various phosphorylated and glycosylated derivatives. SLs form cellular membranes together with glycerolipids and sterols and are distinguished from these other lipids by their chemical structures, physical properties, and specialized enzymatic machinery. SLs utilize two key lipid building blocks, namely long-chain bases and fatty acids, and use serine rather than glycerol as the backbone to which acyl chains are attached. These 
characteristic core features of sphingolipids, together with their head-group modifications, enable them to have unique and essential functions in eukaryotic cells. As depicted in Figure 1, ceramide, the prototype of SLs is generated from the condensation of serine with palmitoyl-CoA resulting in sphingosine formation followed by acylation with fatty acyl CoAs of varied lengths. Ceramide has been the subject of intense investigation due to its structural role in membrane bilayers as well as a signaling molecule regulating a number of cellular processes, including cell proliferation, differentiation, adhesion and cell death [1-4].

Consistent with the key structural role of ceramide in membrane bilayers, the de novo ceramide synthesis pathway is generally envisioned as a major source of the ceramide pool that participates in the maintenance of physico-chemical properties of cell membranes. Ceramide synthesis begins on the cytosolic face of the endoplasmic reticulum (ER) membrane with the condensation of serine and fatty acid-coenzyme A (FA-CoA). This reaction is the rate-limiting step in de novo ceramide synthesis and is catalyzed by the enzyme serine palmitoyltransferase (SPT). A reduction step can yield key intermediates such as sphingosines or long-chain bases, which can be phosphorylated or N-acylated with a second FA-CoA to produce ceramides. Notably, these amide-linked acyl chains are often saturated and tend to be longer than those seen in glycerolipids. However, ceramide neo-genesis is gaining attention in cellular stress response signaling, since enhanced de novo ceramide synthesis occurs in response to chemotherapeutic agents $[7,10]$ due to the activation of SPT or the recently cloned family of ceramide synthases (CerS1-6) [11,12,13]. Particularly, CerSs [14] are highly specific proteins as proven by the special affinity of each CerS for a unique set of fatty acid chains (Table 1). Therefore, an increase in a particular CerS may regulate a specific ceramide pool that may affect the integrity and function of individual cell 
compartments, such as lysosomes, endoplasmic reticulum (ER) or mitochondria. Moreover, since CerS distribution differs among organs [14], the capacity of each individual tissue to withstand apoptotic stimuli may be determined by the characteristic mRNA CerS pattern. For instance, in the liver CerS4 and specially CerS2 are highly expressed, being mainly responsible for long chain ceramides that are thought to play structural roles in cell membranes. However, under certain circumstances hepatic levels of CerS5 may be induced, resulting in increased synthesis of C16-ceramide, which unlike C18-ceramide, is often considered a proapoptotic ceramide, at least in certain cell types [15]. While there is not evidence that HCC-related chemotherapy affect CerSs expression and hence hepatic ceramide levels, CerS1 activation has been detected after UV irradiation, cisplatin or doxorubicin treatment, contributing to the $\mathrm{C} 18$-ceramideinduced death of colon cancer cells and tumor growth suppression in SCID mice $[15,16]$. Similarly, lymphoma cells treated with cannabinoids displayed CerS3 and CerS6 mRNA upregulation, leading to C16, C18 and C24-ceramide accumulation and consequent cell death [17]. Moreover, ionizing radiation induced apoptosis in HeLa cells through de novo ceramide synthesis by the specific activation of CerS isoforms 2 , 5, and 6 that generate opposing anti- and pro-apoptotic ceramides in mitochondrial membranes [18]. These results not only demonstrate the interplay among the CerS proteins in a cell type- and subcellular compartment-specific manner, but also illustrate the complexity and organ-dependent activation of CerS in response to specific proapoptotic stimuli.

In contrast to the role of de novo ceramide synthesis in regulating extra hepatic tumors, the involvement of this particular pathway of ceramide homeostasis in HCC is less established. Nevertheless, alterations in de novo ceramide synthesis have been related to increases in liver cancer incidence. For instance, exposure to fumonisin B1, the most 
typical inhibitor of CerS activity, has been reported to induce liver and kidney tumors in rodents, and studies in maize-consuming human populations suggest a connection between this mycotoxin and the frequency of liver and esophageal cancer in these communities $[19,20]$. In parallel, besides the predominant neural defect, the CerS2deficient mice exhibit strongly reduced levels of ceramide species with very long fatty acid residues (VLCFC) in the liver and develop HCC at the age of 7-10 months old $[21,22]$. In addition, although none of the current strategies recommended for patients with HCC seems to be directly linked to this pathway, de novo ceramide synthesis has been shown to participate in stages that regulate and precede HCC development. For instance, de novo ceramide synthesis has been recently identified as a critical link between the proinflammatory TLR4 receptor and insulin resistance in obesity [23]. Given the association of inflammation and insulin insensitivity with HCC and that obesity is a risk factor for $\mathrm{HCC}$, targeting the de novo ceramide synthesis as a putative pathway regulating $\mathrm{HCC}$ biology is an open question that remains to be further analyzed.

\section{Ceramide generation through hydrolysis of higher sphingolipids}

Breakdown of complex sphingolipids is another effective way of increasing ceramide content in cells [1-4] (Figure 2). In particular, sphingomyelin hydrolysis upon activation of SMases is considered a mechanism for the rapid and transient generation of ceramide, which then impacts on diverse signaling pathways in response to numerous deleterious stimuli, and more importantly, accounts for the critical ceramide pool involved in and responsible for many different pathologies [3,24,25,26,27,28]. Although several mammalian SMases have been characterized, neutral sphingomyelinase 2 (NSMase 2, SMPD3) and acid sphingomyelinase (ASMase, SMPD1) are the most extensively studied enzymes in ceramide generation, and the most relevant in cell death 
regulation and pathology. While NSMase-induced ceramide generation has been described as a critical lipid in inflammatory diseases and oocyte maturation $[29,30]$, ASMase with an optimum $\mathrm{pH}$ of 4.5-5.5, has been extensively described as a signaling intermediate in cell death pathways, of particular relevance in the progression of liver diseases [24,27,28,31]. ASMase catalyzes the formation of ceramide from SM primarily within the endo-lysosomal compartment, although it can be secreted extracellularly through Golgi trafficking as a secretory ASMase (S-SMase) $[3,4]$. The dependence on $\mathrm{Zn}^{2+}$ for proper function is a cardinal differential feature between both ASMase and the secreted form, with the former being $\mathrm{Zn}^{2+}$ independent unlike the secretory enzyme. Both isoforms derive from a proinactive form whose proteolytic processing within the $\mathrm{C}$ terminal leads to the maturation of the endosomal/lysosomal ASMase and the secretory form [32]. Consistent with this process, unlike the pro-ASMase form, the mature ASMase counterpart $(65 \mathrm{kDa})$ is sensitive to the lysosomotropic inhibitor desipramine/imipramine [32]. In addition, deficiency of ASMase results in a lysosomal storage disorder (Niemann-Pick disease) characterized by accumulation of sphingomyelin, with multi-organ consequences. In fact, ASMase knockout mice, initially described as animal model of Niemann-Pick A disease, has played a prominent role in positioning ASMase as a relevant enzyme mediating cell death induced by a variety of stress stimuli and death ligands. Of particular relevance for liver diseases, it has been shown that the liver of ASMase knockout mice is resistant to Fas or TNF exposure [27,33], ischemia/reperfusion [34], $\mathrm{Cu}$ accumulation underlying Wilson disease [28] or diet-induced steatohepatitis [31,35], compared to wild type mice, thus indicating that the ASMase/Cer pathway is a critical axis in liver pathobiology.

As depicted in Figure 2, the de novo synthesized ceramide in the ER can be transformed into other complex derivatives (e.g. gangliosides, cerebrosides such as 
glucosylceramide or as galactosylceramide typically found in neural tissue) in the Golgi, which in turn serve as an additional source of ceramide production. Besides the well known ceramide-sphingomyelin-ceramide relationship, requiring the conversion of ceramide into SM via an ER-Golgi cross-talk involving CERT and SM hydrolysis by SMases described above, a very interesting mechanism of ceramide generation described recently is through the downregulation of sphyngomyelin synthase related protein (SMSr), an ER-resident transmembrane protein. Unlike SMS1 and SMS2, SMSr does not synthesize SM but instead exhibits a ceramide ethanolamine phosphotransferase activity that synthesizes ceramide phosphoethanolamine (CPE). Interestingly, downregulation of SMSr by siRNA induces a dramatic increase in ceramide and glucosylceramide levels that cannot be accounted for by loss of SMSr's CPE-producing activity [36]. Most intriguingly, SMSr silencing induces the trafficking of ceramide to mitochondria leading to cell death [36]. Whether this function of SMSr is a general phenomenon present in different cell types needs to be further established. Nevertheless, other complex glycosphingolipids (such as gangliosides or cerebrosides) may be an additional source of ceramide production. For instance, detachment of sugar unit from ganglioside GM3 by Neu3 has been shown to generate plasma membrane ceramide in human fibroblasts [37]. Neu3-overexpressing fibroblasts were characterized by a reduced proliferation rate and higher basal number of apoptotic cells in comparison with wild-type cells. Although, the participation of this additional mechanism of ceramide generation by glycosphingolipid hydrolysis has not been clearly established in hepatocarcinogenesis, the potential use of activators of these proteins to promote the hydrolysis of complex sphingolipids into ceramide may be of interest to increase cancer therapy efficacy and deserves further investigation.

Ceramide catabolism: ceramidases and glucosylceramide synthase. 
Consistent with the effects described in other cell types, the increase in hepatocellular ceramide levels triggers cell death via mechanisms including loss of mitochondrial membrane potential and release of proapototic intermembrane mitochondrial proteins $[38,39,40]$, activation of JNK [41,42], inhibition of AKT [43] or ceramide-mediated dephosphorylation of the BH3-only protein Bad [44]. Interestingly, although ceramide is a well-characterized proapoptotic SLs it can be transformed into other nonapoptotic derivatives via different mechanisms. Among them, ceramide glycosylation by glucosylceramide synthase (GCS) into glucosylceramide (Figure 2), and ceramide catabolism to sphingosine 1 phosphate (S1P) after the consecutive action of ceramidases and sphingosine kinases are of major relevance in liver pathophysiology. As expected from the relative balance between these proapoptotic and antiapoptotic SLs forms, targeting these ceramide catabolic pathways may be of therapeutic value to kill tumor cells.

Three ceramidase (CDase) isoforms with distinctive $\mathrm{pH}$ optimums, acid, alkaline and neutral, have been described [45], being their relative contribution to cell death dependent on the stimuli and the cell type studied. Although the neutral CDase has been shown to play a protective role against cytokine-induced cell death in mesangial cells [46], the acidic CDase in the isoform that has been more clearly involved in the regulation of cancer progression. For instance, the overexpression of acid CDase protected L929 cells against TNF-induced apoptosis [47], while its upregulation in prostate cancer cells conferred resistance to radiation [48], suggesting that acid CDase overexpression is a characteristic feature of more advanced and aggressive prostate cancers. In accordance with these results, inhibition of acid CDase by a ceramide analogue, B13, induced apoptosis in cultured human colon cancer cells, and prevented liver metastases in vivo [49], whereas its genetic down regulation by small interfering 
RNA (siRNA) or the administration of the small molecule acid CDase inhibitor, LCL385, sensitized PPC-1 cells to radiation and significantly decreased tumor xenograft growth [48]. Noteworthy, this mechanism of ceramide elimination may play a relevant role in the resistance of human liver cancer cells against chemotherapy. In this regard, daunorubicin (DNR) activated acid CDase post-transcriptionally in human (HepG2 cells) or mouse (Hepa1c1c7) hepatoma cell lines as well as in primary cells from murine liver tumors, but not in cultured healthy mouse hepatocytes [41]. In addition, acid CDase silencing by siRNA or pharmacological inhibition sensitized hepatoma cells to DNR-induced cell death and reduced tumor growth in murine liver tumor xenografts after DNR therapy [41]. Interestingly, the synergistic effect of ceramidase inhibitors in combination with DNR administration is not restricted to this chemotherapeutic agent or to HCC. For instance, recent reports described the synergism between $\mathrm{N}$-(4-hydroxyphenyl) retinamide and acid CDase inhibition in prostate cancer cells [50], while acid CDase expression has been shown to modulate the sensitivity of melanoma cells to dacarbazine [51].

Besides the reduction in ceramide levels, acid CDase activation contributes to the resistance of cancer cells to chemotherapy by the generation of S1P. S1P is a potent antiapoptotic, prosurvival SLs due to a combined mechanism of action including the antagonism of ceramide-mediated cell death pathways from inside cells [52,53], as well as by activating proliferative pathways from outside the cell via five specific $G$ proteincoupled S1P receptors $\left(\mathrm{S}_{1} \mathrm{PR}_{1-5}\right)$ [54]. S1P production requires sphingosine generation from ceramide following its deacylation by ceramidase, and the resulting sphingosine formation is then phosphorylated by sphingosine kinases (SK). Two SK isoforms (SK1 and SK2) have been described and characterized. Although these forms seem redundant in normal cells their specific increase in different tumor cell types has been associated 
with cancer progression. Particularly, increased levels of the SK1 protein and/or mRNA has been reported in stomach, brain, lung, colon or breast cancers, with a correlation between SK1 expression and tumor grade or decreased patient survival [54], suggesting S1P as potential target to control tumor growth and angiogenesis [55].

These divergent effects of ceramide and S1P have led to the definition of a ceramideS1P rheostat model, whereby the fate of tumor cells is established by the relative levels of these bioactive sphingolipids. Consistent with this notion, CDase and/or SK antagonism would promote tumor cell death by a dual mechanism involving the increase of intracellular ceramides while simultaneously decreasing the antiapoptotic pathways induced by S1P. In this regard, and consistent with previous observations in HCC following acid CDase inhibition [41], blocking SK activity has been shown effective to kill HCC cells [56], and more interestingly, to decrease xenograft tumor growth in combination with sorafenib administration.

Another important mechanism of ceramide elimination is mediated by GCS. Glucosylceramide generation from ceramide glycosylation has been also suggested as an effective cellular strategy whereby cancer cells become resistant to chemotherapy. In fact, pharmacological inhibition or RNA interference of GCS expression has been proved useful to potentiate the anticancer activity of several compounds $[57,58,59]$. In addition, GCS activation underlies the resistance of many cancer cells to chemotherapy $[60,61]$, indicating that GCS is a key determinant of the multidrug resistance phenotype. In spite of the overwhelming evidence of GCS in chemotherapy resistance, there is little data involving GCS in the modulation of liver cancer biology and therapy. For instance, pharmacological GCS inhibition has been proved of value to increase effectiveness of cancer therapy in liver cancer [62]. Although certain chemosensitizing effect of GCS inhibitors have been observed in hepatoma cells, other mechanisms unrelated to GCS 
might have played a role in this respect. For instance, although ceramide is a wellrecognized SLs that promotes cell death, other species derived from GCS may also share this function. In this regard, GD3 ganglioside, for which glucosylceramide provides the backbone, is a bioactive lipid with a prominent role in liver pathologies [63]. Therefore, the regulation of ceramide along with the subsequent GD3 generation in the Golgi may constitute an effective measure to control hepatocellular cancer cell death.

\section{Glycosphingolipids: role of the prototype GD3 ganglioside in cell death.}

Alterations in the pattern of glycosphingolipids have been largely reported in tumor cells, probably reflecting changes in critical enzymes in this pathway such as that observed with GCS expression and activity $[64,65]$. Taking advantage of this abnormal glycosphingolipid content, clinical trials using ganglioside-based vaccines are ongoing based on the identification of gangliosides as tumor antigens due to their abundance on the plasma membrane of specific tumor cells, such as in melanoma. In general, the increase in ganglioside levels in tumor cells is usually restricted to those with lower sialic content [66], while more complex gangliosides, such as GD3, are not modified in transformed tissues, as it would be speculated based on its pro-apoptotic function.

Several mechanisms whereby GD3 promotes cell death have been described. In addition to the intracellular redistribution of GD3 in response to TNF/Fas leading to mitochondrial targeting [67], GD3-mediated NF- $\kappa B$ inhibition is perhaps one of the most relevant ones due to the importance of the $\kappa \mathrm{B}$-dependent induction of survival programs that antagonize HCC death contributing to the promotion of hepatocarcinogenesis. This novel role of GD3 is of particular significance due to the identification of NF- $\mathrm{KB}$ activation by hypoxia-generated ROS, through a Src-mediated tyrosine phosphorylation, described in neuroblastoma and HCC tumor cell lines [68]. In 
this pathway, hypoxia stimulates mitochondrial-induced ROS generation in complex III of the mitochondrial respiratory chain, which in addition to the activation of HIF-1 $\alpha$

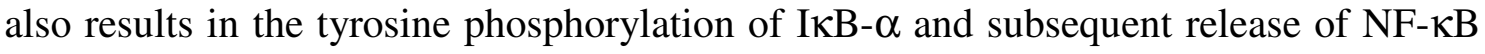
DNA binding complexes p52/50 and p50/p50. Besides activation of survival pathways, $\mathrm{NF}-\mathrm{KB}$ stimulation induces a protective program against oxidative stress including the overexpression of Manganese Superoxide Dismutase (MnSOD). Thus, given this central role of NF- $\mathrm{KB}$ in cancer cell survival, its antagonism by GD3 may be of relevance as a novel strategy to curtail neoplasic growth, and particularly, to reduce tumor progression in liver cancer [69].

As alluded above, besides the blockade of NF- $\mathrm{KB}$ activation, GD3 also interacts with mitochondria, eliciting a burst of ROS due to the targeting of complex III of the mitochondrial respiratory chain that induce the loss of mitochondrial membrane potential $[69,70]$. As a consequence, GD3 contributes to the release of apoptogenic proteins from the intermembranal space to the cytosol, such as cytochrome c and SMAC/Diablo, and activates caspase dependent apoptotic cell death. [67,70,71,72]. Of interest, these proapoptotic effects were induced in hepatocarcinoma cells when GD3 was exogenously administered in combination with anticancer therapy such as antracyclines or ionizing radiation [73,74]. Following the exploitation of these proapopoptotic features of GD3, it has been recently observed that GD3 synthase overexpression sensitized human HCC cells to hypoxia-induced cell death. This processed was mediated by stimulation of GD3 from endogenous GM3 resulting in enhanced generation of mitochondrial-derived ROS that reduced HCC progression in a xenograft model [69]. In addition, mitochondrial trafficking of GD3 has been shown to function as a platform where death signals integrate to optimize the function of Bax to induce mitochondrial membrane permeabilization and release of apoptogenic factors 
[75]. Given the multifactorial nature of GD3 in promoting cell death by a dual mechanism involving mitochondrial targeting and engagement of the apoptosome while disabling survival pathways, these finding illustrate the potential relevance of GD3 in cancer cell biology and therapy. However, whether GD3 synergizes with currently used therapy in the treatment of HCC such as sorafenib deserves further investigation.

\section{$\underline{\text { Liposomal administration of ceramide as a chemosensitizer. }}$}

Consistent with the ability of ceramide to regulate cell death pathways at different levels, its forced accumulation may be an effective strategy to increase the efficacy of current cancer therapy. However, this approach has to take in consideration that raising intratumoral ceramide levels depends on a number of factors, including specific characteristics of each cancer cell and the particular alterations of ceramide metabolism induced by chemotherapeutic agents. To overcome these potential pitfalls an attractive approach is the delivery of ceramide directly to target cells via administration of

systemic liposomal particles [76,77]. More importantly, pegylated nanoliposomal formulations containing ceramide have demonstrated efficacy as anti-cancer therapy both in vitro and in vivo [78,79]. Indeed, nanoliposomal C6-ceramide administration has been shown to antagonize pro-survival (AKT) and pro-mitogenic (ERK) signaling pathways, resulting in reduced markers of microvascularisation/angiogenesis at tumor sites [80]. Of particular relevance, the therapeutic outcome of nanoliposomal C6ceramide occurred essentially free of toxic collateral effects, being selectively proapoptotic for breast cancer as well as melanomas but not their corresponding normal tissues such as normal mammary epithelial cells and melanocytes. Recently, it has been shown that administration of nanoliposomal C6-ceramide is effective in treating in vitro and in vivo human models of HCC [79]. Besides its direct apoptotic effects towards SKHEP-1 cells, systemic administration of ceramide nanoliposomes in mice engrafted with 
SK-HEP-1 cells reduced tumor vascularisation, and proliferation, induced tumor cell apoptosis, decreased phosphorylation of AKT and blocked in vivo tumor growth. These studies not only provide evidence that exogenous ceramide delivery may be of value in slowing HCC progression but also suggest that liposomal ceramide administration along with other chemotherapeutic agents may be an attractive anticancer approach. Of note, it has been recently shown that the administration of nanoliposomal ceramide with sorafenib synergistically inhibits melanoma and breast cancer tumor development [80], providing solid grounds for clinical trials evaluating the efficacy of combining sorafenib with nanoliposomal ceramide for the treatment of HCC.

\section{Sphingolipidomics in HCC treatment.}

As described above, the realm of SLs contains elements with opposing functions in terms of cell death regulation, with some promoting apoptotic events such as ceramide and ganglioside GD3, while others stimulate cell proliferation and activation of survival pathways, including S1P and ceramide 1 phosphate. Hence, from this scenario it becomes clear that this diversity of SLs species may be even more complex in transformed cells undergoing phenotypic changes towards malignant transformation. Although there is growing evidence pointing to a role of SLs in the regulation of cancer cell biology, the lack of a detailed description of the alterations in specific SLs species in particular cancer types has hampered the use of sphingolipid-based strategies in cancer treatment. However, the dawn of technological advancement allowing lipidomic analyses in recent years and the establishment of protocols and techniques to quantify SLs content of tissue samples [81,82] opens the door to the generation of sphingolipidomic pictures of different types of cancer in the near future. The determination of distinctive sphingolipidic signatures in specific tumor types will allow the development of cancer treatment based on intervention in sphingolipid metabolism 
[83], while future clinical testing of circulating bioactive sphingolipids in human blood may provide important information as specific markers for cancer progression [84].

Moreover, the identification of specific anticancer compounds in the modulation of SLs metabolism in different cancer tissues would be relevant for potential treatments. In the case of HCC, this approach would entail the characterization of the SLs signature both in HCC tumors and in the adjacent non-tumor tissue. In addition, the sphingolipidomic analysis of primary vs metastatic liver tumors would allow the identification of characteristic features in each liver tumor that will help in the design of combinatorial therapies with chemotherapeutic agents to increase the success of cancer treatments in the liver.

\section{Cholesterol and chronic liver disease leading to HCC}

Cholesterol is a key component of cellular membranes, which plays a crucial role in their integrity and function. Cholesterol regulates the permeability between cellular compartments and membrane fluidity [85]. Moreover, cholesterol induces membrane packing in specific microdomains of the plasma membrane, acting as a platform for membrane-associated signaling proteins [86], and induces lateral lipid segregation and regulates membrane elasticity. Due to this role in modulating membrane structure and function cholesterol levels need to be tightly regulated; in addition, increases in cell cholesterol content may be toxic, particularly if redistributed to specific membranes bilayers such as mitochondria (see below). Cell requirement for cholesterol is fulfilled either by its uptake from nutrients and lipoproteins or by de novo synthesis from acetylCoA in the so-called mevalonate pathway [87]. Cholesterol biosynthesis occurs in all mammalian cells, although the pathway operates at higher capacity in the liver and other steroidogenic tissues, such as adrenal cortex and reproductive tissues. Cholesterol is synthesized at the ER by a complex process involving the proteolytic activation of 
transcription factor SREBP-2 by a ER-Golgi cross talk that involves the escort from the ER to the Golgi of the inmature SREBP-2 form where is processed into its mature form by proteases SP-1 and SP-2 [88,89]. The migration of the mature SREBP-2 form to the nuclei induces the transcriptional activation of target genes, including HMG-CoA reductase, the rate-limiting enzyme in this pathway [90,91]. Although the role of cholesterol in pathogenesis has been best recognized in cardiac and brain vascular diseases, emerging evidence points to cholesterol as a key factor in several disorders, including metabolic liver diseases such as alcoholic (ASH) and nonalcoholic steatohepatitis (NASH) [92]. ASH/NASH is an intermediate stage of fatty liver disease which can further progress to cirrhosis and HCC. Due to the rising prevalence of obesity worldwide, NASH constitutes a global health concern requiring the urgent need for more effective therapies. Recent studies indicated the accumulation of free cholesterol in obesity and diabetes models, which leads to the nuclear translocation of SREBP-2, thus contributing to the transition from steatosis to NASH [93]. Moreover, studies in patients with NASH indicated the stimulation of free cholesterol levels compared with those exhibiting simple steatosis, effects that were accompanied by increased expression of SREBP-2 and StAR [94], a mitochondrial cholesterol transporting polypeptide (see below). Thus, due to the evolution of ASH/NASH into HCC and the expected increase of HCC as the end-stage of chronic liver diseases, it is critical to improve the current availability of treatment options for HCC.

Cholesterol has been gradually recognized as a critical emerging player in liver diseases, the bulk for this function resides in the small but powerful pool of cholesterol in mitochondrial membranes [92]. Compared to other membrane bilayers, mitochondria are cholesterol-poor organelles with estimates of $0.5-3 \%$ of the total cholesterol pool. Despite its low abundance, the mitochondrial cholesterol pool plays significant 
physiological roles in liver and steroidogenic tissues, acting as a precursor for the synthesis of bile acids and steroidogenic hormones, respectively. Although the regulation of mitochondrial cholesterol is still poorly understood, significant progress in this particular aspect has been made with the characterization of specialized carriers that belong to the family of steroidogenic acute regulatory protein StAR, which function not only in the delivery of cholesterol from extramitochondrial sources to mitochondria but also in the trafficking from the outer membrane to inner membrane for metabolism $[95,96,97]$. In addition to the StAR family, other proteins known to bind cholesterol have been recently characterized in the regulation of mitochondrial cholesterol.

Although caveolin-1 is best recognized as a protein residing in defined domains of the plasma membrane, recent observations indicated that it is also present in other membrane bilayers. Indeed, caveolin-1 has been localized in other non-caveolae sites, including mitochondria. Pioneering work by Andersson et al using cell fractionation and immunoelectron microscopy described the localization of caveolin-1 in mitochondria of epithelial cells, including hepatocytes [98]. While these findings were largely ignored, a recent report confirmed the original observations of Andersson et al, validating the presence of caveolin-1 in hepatic mitochondria [99]. Moreover, Mastrodonato et al reported enhanced levels of caveolin-1 in mitochondria from steatotic livers, indicating that increased hepatic cholesterol traffics to mitochondria where it distributes between the outer and inner membrane. Consistent with these findings we have recently observed that deficiency of caveolin-1 leads to increased mitochondrial cholesterol levels both in hepatic and brain mitochondria [100]. Moreover, caveolin-1 does not distribute homogeneously in hepatic mitochondria but partitions largely in detergent insoluble fractions in colocalization with markers defining mitochondria associated 
membranes (MAM) (Fernandez et al, manuscript in preparation), consistent with recent observations in brain mitochondria [101].

Despite its small content, the mitochondrial pool of cholesterol has been revealed as an important player in different diseases, playing a prominent role in neurodegeneration and hepatopathies $[93,94,102,103,104]$. Of particular relevance to liver diseases, using nutritional and genetic models of hepatic steatosis, it has been shown that mitochondrial cholesterol loading sensitizes to TNF- and Fas-induced steatohepatitis, increasing the hepatocellular susceptibility to cytokines via mitochondrial glutathione (mGSH) depletion [103]. In a similar fashion, the diminished mitochondrial capacity to cope with reactive oxygen species seems to be responsible for the enhanced sensitivity to liver damage during ischemia/reperfusion, as observed in murine steatotic livers that presented mitochondrial accumulation of cholesterol [104]. Therefore, if mitochondrial cholesterol is a critical factor contributing to the progression of liver diseases, its regulation may be of clinical significance in the early phases of HCC development. Based on their ability to modulate mitochondrial cholesterol trafficking, caveolin-1 and StAR may constitute novel targets for intervention to control cholesterol accumulation in mitochondria and hence in the progression of chronic liver diseases. However, their specific contribution in mitochondrial cholesterol regulation would be opposite, with caveolin-1 preventing while StAR favoring mitochondrial cholesterol loading (Figure 3). This model is consistent the phenotype observed in caveolin-1 knockout mice [100] while StAR silencing abrogates mitochondrial cholesterol accumulation in hepatocytes [105].

In addition to the unphysiological enrichment of mitochondria in cholesterol during liver disease progression and HCC, another level of deregulation of cholesterol homeostasis lays in the de novo synthesis of cholesterol in cancer cells (Figure 4). One 
essential mechanism to control de novo cholesterol synthesis is the feedback and transcriptional control of HMG-CoAR by cholesterol. HMG-CoAR resides in the ER linked via its N-terminal domain and sterol and nonsterol end products of the mevalonate pathway control HMG-CoAR, to allow for continued production of essential nonsterol isoprenoids. A fundamental mechanism for feedback control involves the rapid degradation of HMG-CoAR, mediated by Insig-1 and Insig-2, two ER-resident proteins. Accumulation of sterols in ER membranes triggers binding of the membrane domain of HMG-CoAR to a specialized protein, which carries a membraneanchored ubiquitin ligase, gp78, which signals the ubiquitination of the reductase and its proteasomal degradation [106,107]. Another mechanism regulating cholesterol synthesis is the availability of oxygen. Most of the oxygen required in this process is involved in the sequential removal of three methyl groups of lanosterol, resulting in zymostenol. Recent findings have reported that hypoxia stimulates degradation of HMG-CoAR through both accumulation of lanosterol and HIF-1 $\alpha$-mediated Insigs induction [108].

Given these regulatory factors of the de novo cholesterol synthesis, the recognized accumulation of cholesterol during HCC development [109] seems a conundrum. As a critical component of membrane bilayers, cholesterol accumulates in HCC to support the rate of cell proliferation and formation of new membrane bilayers during tumor growth and this response occurs with the resistance of HMG-CoA reductase to proteasomal degradation. Moreover, since hypoxia is a key feature of solid tumors due to abnormal vessels architecture, cholesterol synthesis in growing HCC tumors seems insensitive to the limited oxygen availability. Further understanding of these abnormal features may be key to design specific armamentarium to disrupt the reliance of growing $\mathrm{HCC}$ on cholesterol requirement to promote tumor growth. As described 
below, much of this dependence on cholesterol in hepatocarcinogenesis is via its preferred trafficking to mitochondria.

\section{Mitochondrial cholesterol in HCC treatment}

As detailed above, cancer cells exhibit critical metabolic changes regarding the cholesterol homeostasis, as best illustrated by the ability of solid tumors to synthesize cholesterol under hypoxia, which contrasts with the physiological requirement for oxygen in the transformation of lanosterol into cholesterol via 9 redox reactions. In addition to this continued cholesterol synthesis in growing tumor cells, we have recently observed the stimulation of cholesterol trafficking to mitochondria from HCC cells. Since its description almost 30 years ago in heterotopic Morris hepatoma xenografts in Buffalo rats [110], the mitochondrial enrichment in cholesterol has been viewed mainly as a key factor underlying the mitochondrial dysfunction characteristic of cancer cells [109]. Indeed, in situ cholesterol enrichment in hepatic mitochondria impairs the acceptor control ratio, oxidative phosphorylation and the function of specific MPT components. For instance, cholesterol loading in rat liver mitochondria prevented atractyloside to induce the m-conformational change in ANT to cause MPT and release proapoptotic proteins into the cytosol [111].

However, in addition to this putative effect of cholesterol in the regulation of mitochondrial function of cancer cells, we focused on the role of mitochondrial cholesterol in chemotherapy sensitivity and cell death regulation. Established human, rat and mouse HCC exhibit increased mitochondrial cholesterol levels with respect to non-tumor mitochondria from human, rat or mouse liver [112], consistent with previous studies in solid hepatoma mitochondria compared with host liver [110, 113,114,115]. Of interest, the up-regulation of mitochondrial cholesterol content in HCC correlates with increased expression of SREBP-2 and HMG-CoA reductase, validating the cholesterol 
deregulation of cancer cells. In addition to these changes, HCC cells exhibit increased StAR mRNA levels, which correlate with the degree of mitochondrial cholesterol loading. This selective trafficking of cholesterol to mitochondria reduces the sensitivity to chemotherapy agents acting via MPT. For instance, while rat and human HCC become resistant to lodinamide or daunorubicin-mediated mitochondrial membrane permeabilization and cytochrome c release [112], these cells are sensitive to bafilomycin A, an inhibitor of the vacuolar type H+-ATPase that impairs lysosomal function and promotes apoptosis independently of mitochondrial membrane permeability. Moreover, StAR silencing following siRNA treatment sensitized human and rat HCC to chemotherapy, demonstrating that the accumulation of mitochondrial cholesterol protects HCC against cell death by disabling the ability of mitochondria to undergo MPT and mitochondrial membrane permeabilization.

Since cholesterol is known to regulate membrane properties $[85,86]$, we hypothesized that the mechanisms of the mitochondrial cholesterol-induced resistance of HCC to chemotherapy might imply alterations in membrane dynamics. Indeed, isolated mitochondria from HepG2 or H35 hepatoma cells exhibit higher order, which is reversed by cholesterol extraction with methyl- $\beta$-cyclodextrine or fluidization by the fatty acid derivative $\mathrm{A}_{2} \mathrm{C}$, resulting in increased MPT and release of cytochrome $\mathrm{c}$ in response to $\mathrm{Ca} 2+$ loading, superoxide anion of active Bax. Thus, these data indicate that mitochondrial cholesterol loading in $\mathrm{HCC}$ is antiapoptotic and protects HCC mitochondria against membrane permeabilization by increasing membrane order. To further confirm this possibility, similar data was observed in large unilamelar vesicles (LUVs) of defined lipid composition entrapping fluorescent dextrans following active Bax exposure. Quite interestingly, while Bax efficiently released fluorescent dextrans into the medium in control LUVs, cholesterol-containing LUVs were resistant to Bax- 
mediated permeabilization [112], reproducing the effects observed in mitochondria from HCC. Moreover, the data indicated that cholesterol reduced the capacity of Bax to penetrate into the membrane, which is considered a critical step in Bax activation. Thus, through modulation of membrane order and curvature stress, cholesterol regulates the ability of mitochondria to become permeabilized in response to a wide range of proapoptotic agents including chemotherapy, protecting $\mathrm{HCC}$ against cell death. Moreover, observations in HeLa cells treated with U18666A, which results in mitochondrial cholesterol loading, indicated a delayed release of Smac/DIABLO and cytochrome c, as well as in Bax oligomerization and partial protection against stressinduced apoptosis [116]. These results in cervix cancer cells suggest that the influence of mitochondrial cholesterol on tumor progression observed in HCC is not exclusive for liver cancer, suggesting that the abnormal homeostasis of cholesterol, in particular its mitochondrial trafficking, may be a general key feature of carcinogenesis and a novel target for therapeutic intervention. In line with this possibility, treatment of HCC with lovastatin both in vitro and in vivo reduced tumor cholesterol content, including the mitochondrial pool, resulting in increased susceptibility to chemotherapy and reduced tumor growth [112]. Although statins are known to regulate carcinogenesis via mechanisms independent on the cholesterol lowering effects [117], our findings add a novel mechanism of action of statins by indirectly regulating the trafficking of mitochondrial cholesterol. 


\section{CONCLUDING REMARKS}

HCC is one of the leading causes of cancer-related deaths in the world, and constitutes the end stage of chronic liver diseases. Current available therapy is limited and unfortunately effective treatment can only be offered to a selected group of patients. Given the progression of metabolic liver diseases such as ASH/NASH towards HCC and their association with obesity and type 2 diabetes, there is an urgent need to increase the therapeutic options for patients suffering HCC. In addition to genetic studies linking the pattern of gene expression with prognosis and disease recurrence, a better understanding of the molecular pathways contributing to HCC may pave the way for novel therapeutic avenues. HCC is an extremely complex and heterogeneous disease whose progression is often determined by the initial cause or insult leading to hepatocellular death and uncontrolled proliferation. In addition to the genetic and epigenetic reprogramming occurring in HCC, abnormal signaling pathways and lipid homeostasis contribute as well to the progression of HCC. Consistent with their crucial roles in membrane structure and function, cholesterol and SLs have emerged as key lipid mediators that regulate a number of cellular processes, some of which are essential to neoplasic transformation and tumor growth, such as differentiation, proliferation and cell death. In this regard, recent evidence and current studies validate a role for altered cholesterol and SLs metabolism as a critical metabolic component contributing to key aspects of HCC, including cell death and chemotherapy resistance. Of particular relevance is the realm of SLs, which encompass not only key mediators promoting cell death (e.g. ceramide and ganglioside GD3) but also other derivatives (e.g. S1P) that sustain cell survival and proliferation. While many of the current drugs used to treat solid tumors including HCC generate proapoptotic ceramide, a common strategy of advanced cancers is the reprogramming and induction of antiapoptotic SLs to 
antagonize the therapeutic effect of the former. In addition to this scenario, HCC exhibit abnormal cholesterol metabolism and homeostasis, and undergo an unphysiological trafficking towards mitochondria to shield the outer membrane to resist permeabilization when challenged with therapeutic drugs. Thus, a better understanding of the metabolic disturbances of ceramide and cholesterol metabolism may prove useful to design novel and more effective therapeutic combinations, which hopefully will be available soon in the near future to better manage HCC patients. For instance statins, already taken by a high number of patients to control cardiovascular events may be also of potential interest to control HCC progression, particularly in association with other current chemotherapies. Besides statins, inhibitors of other enzymes in cholesterol synthesis, such as squalene synthase, may specifically prevent cholesterol without interfering with isoprenoid synthesis, or even drugs that prevent cholesterol absorption, may be of potential use in HCC [118]. In addition, to control ceramide/cholesterol metabolism could improve the management of the progression of metabolic liver diseases ASH/NASH and ultimately influence the incidence of HCC. 


\section{ABBREVIATIONS}

ASH: alcoholic steatohepatitis

ASMase: acid sphingomyelinase

CDase: ceramidase

Cer: ceramide

CerK: ceramide kinase

CerS: ceramide synthase

CERT: ceramide transport protein

DNR: daunorubicin

ER: endoplasmic reticulum

FA: fatty acid

GCS: glucosylceramide synthase

GlcCer: glucosylceramide

GSL: glycosphingolipids

GSH: glutathione

HCC: hepatocellular carcinoma

LUV: large unilamelar vesicles

MPT: mitochondrial permeability transition

NASH: non-alcoholic steatohepatitis

NSMase: neutral sphingomyelinase

ROS : reactive oxygen species

S1P: sphingosine 1 phosphate

SK: sphingosine kinase

SL: sphingolipid

SMase: sphingomyelinase 
SMS: sphingomyelin synthase

SPT: serine palmitoyl transferase

SREBP: sterol regulatory element-binding protein

StAR: steroidogenic acute regulatory protein

VLCFA: very long chain fatty acid 


\section{TABLE 1.}

\begin{tabular}{lll}
\hline Name & Tissue mRNA expression profile & \multicolumn{1}{c}{$\begin{array}{c}\text { Acyl chain-length } \\
\text { specificity }\end{array}$} \\
\hline CerS1 & Brain, skeletal muscle, testis & C18 \\
CerS2 & Kidney, liver & C20, C22, C24, C26 \\
CerS3 & Testis, skin & C22, C24, C26 \\
& & C18, C20, C22, C24, \\
CerS4 & skin, leukocytes, heart, liver & C26 \\
& & \\
CerS5 & Low expression in all tissues & C16 \\
& &
\end{tabular}

Human ceramide synthases expression. All six enzymes (CerS1-6) proceed from different genes, have dissimilar pattern of tissue expression and display specific activities towards the length of acyl-CoA substrates. Main tissues of mRNA expression and acyl chains with higher affinity for each individual CerS are shown. 


\section{FIGURE LEGENDS}

Figure 1. Chemical structure of ceramide. After the condensation of serine with palmitoyl-CoA, by the action of the serine palmitoyl transferase (SPT), the long-chain base sphinganine is attached to fatty acyl CoAs of different length as an amide linkage producing ceramide (C16 depicted) throught ceramide synthase (CS) activity. Although ceramide is the prototype of SLs, there are other modifications in the structure of the long-base chain other than the desaturation as shown, and include the hydroxylation in carbon 4, yielding phytosphingosine or phosphorylation in the hydroxyl group, yielding ceramide 1 phosphate (not shown here).

Figure 2. Schematic representation of main cellular pathways involved in ceramide metabolism in the liver.

Figure 3. Scheme illustrating the regulation of mitochondrial cholesterol during HCC. Although the levels of cholesterol in mitochondria are low, during HCC cholesterol accumulates in mitochondrial membranes. Both caveolin-1 and StAR regulate cholesterol trafficking in a dynamic and bidirectional fashion. Data is consistent with caveolin-1 negatively regulating mitochondrial cholesterol as opposed to StAR which positively moves cholesterol not only towards mitochondrial membranes but also between the outer and the inner membrane.

Figure 4. Simplified representation of main enzymatic reactions involved in cholesterol biosynthesis in mammalian cells. Statins prevent mevalonate formation from HMGCOA, while inhibitors under the sterol branch of Farnesyl-PP, such as squalene synthase, may block cholesterol synthesis without perturbing isoprenoid production. 


\section{REFERENCES}

[1] Hannun, Y. A.; Obeid, L. M., Principles of bioactive lipid signalling: lessons from sphingolipids. Nat Rev Mol Cell Biol 2008, 9 (2), 139-150.

[2] Morales, A.; Lee, H.; Goni, F. M.; Kolesnick, R.; Fernandez-Checa, J. C., Sphingolipids and cell death. Apoptosis 2007, 12 (5), 923-939.

[3] Smith, E. L.; Schuchman, E. H., The unexpected role of acid sphingomyelinase in cell death and the pathophysiology of common diseases. FASEB $J$ 2008, 22 (10), $3419-3431$.

[4] Canals, D.; Perry, D. M.; Jenkins, R. W.; Hannun, Y. A., Drug targeting of sphingolipid metabolism: sphingomyelinases and ceramidases. Br J Pharmacol 2011, $163(4), 694-712$.

[5] Ogretmen, B.; Hannun, Y. A., Biologically active sphingolipids in cancer pathogenesis and treatment. Nat Rev Cancer 2004, 4 (8), 604-616.

[6] Ryland, L. K.; Fox, T. E.; Liu, X.; Loughran, T. P.; Kester, M., Dysregulation of sphingolipid metabolism in cancer. Cancer Biol Ther 2011, 11 (2), 138-149.

[7] Ponnusamy, S.; Meyers-Needham, M.; Senkal, C. E.; Saddoughi, S. A.; Sentelle, D.; Selvam, S. P.; Salas, A.; Ogretmen, B., Sphingolipids and cancer: ceramide and sphingosine-1-phosphate in the regulation of cell death and drug resistance. Future Oncol 2010, 6 (10), 1603-1624.

[8] Stancevic, B.; Kolesnick, R., Ceramide-rich platforms in transmembrane signaling. FEBS Lett 2010, 584 (9), 1728-1740.

[9] Scheffer, L.; Raghavendra, P. R.; Jing-Jing, M.; Acharya, J. K., Ceramide Transfer Protein and Cancer. Anticancer Agents Med Chem 2011.

[10] Reynolds, C. P.; Maurer, B. J.; Kolesnick, R. N., Ceramide synthesis and metabolism as a target for cancer therapy. Cancer Lett 2004, 206 (2), 169-180. 
[11] Wang, H.; Maurer, B. J.; Reynolds, C. P.; Cabot, M. C., N-(4hydroxyphenyl)retinamide elevates ceramide in neuroblastoma cell lines by coordinate activation of serine palmitoyltransferase and ceramide synthase. Cancer Res 2001, 61 (13), 5102-5105.

[12] Bose, R.; Verheij, M.; Haimovitz-Friedman, A.; Scotto, K.; Fuks, Z.; Kolesnick, R., Ceramide synthase mediates daunorubicin-induced apoptosis: an alternative mechanism for generating death signals. Cell 1995, 82 (3), 405-414.

[13] Carracedo, A.; Lorente, M.; Egia, A.; Blazquez, C.; Garcia, S.; Giroux, V.; Malicet, C.; Villuendas, R.; Gironella, M.; Gonzalez-Feria, L.; Piris, M. A.; Iovanna, J. L.; Guzman, M.; Velasco, G., The stress-regulated protein p8 mediates cannabinoidinduced apoptosis of tumor cells. Cancer Cell 2006, 9 (4), 301-312.

[14] Levy, M.; Futerman, A. H., Mammalian ceramide synthases. IUBMB Life 2010, $62(5), 347-356$.

[15] Senkal, C. E.; Ponnusamy, S.; Bielawski, J.; Hannun, Y. A.; Ogretmen, B., Antiapoptotic roles of ceramide-synthase-6-generated C16-ceramide via selective regulation of the ATF6/CHOP arm of ER-stress-response pathways. FASEB $J \mathbf{2 0 1 0}, 24$ (1), 296-308.

[16] Karahatay, S.; Thomas, K.; Koybasi, S.; Senkal, C. E.; Elojeimy, S.; Liu, X.; Bielawski, J.; Day, T. A.; Gillespie, M. B.; Sinha, D.; Norris, J. S.; Hannun, Y. A.; Ogretmen, B., Clinical relevance of ceramide metabolism in the pathogenesis of human head and neck squamous cell carcinoma (HNSCC): attenuation of $\mathrm{C}(18)$-ceramide in HNSCC tumors correlates with lymphovascular invasion and nodal metastasis. Cancer Lett 2007, 256 (1), 101-111. 
[17] Gustafsson, K.; Sander, B.; Bielawski, J.; Hannun, Y. A.; Flygare, J., Potentiation of cannabinoid-induced cytotoxicity in mantle cell lymphoma through modulation of ceramide metabolism. Mol Cancer Res 2009, 7 (7), 1086-1098.

[18] Mesicek, J.; Lee, H.; Feldman, T.; Jiang, X.; Skobeleva, A.; Berdyshev, E. V.; Haimovitz-Friedman, A.; Fuks, Z.; Kolesnick, R., Ceramide synthases 2, 5, and 6 confer distinct roles in radiation-induced apoptosis in HeLa cells. Cell Signal 2010, 22 (9), $1300-1307$.

[19] Riley, R. T.; Enongene, E.; Voss, K. A.; Norred, W. P.; Meredith, F. I.; Sharma, R. P.; Spitsbergen, J.; Williams, D. E.; Carlson, D. B.; Merrill, A. H., Jr., Sphingolipid perturbations as mechanisms for fumonisin carcinogenesis. Environ Health Perspect 2001, 109 Suppl 2, 301-308.

[20] Wild, C. P.; Gong, Y. Y., Mycotoxins and human disease: a largely ignored global health issue. Carcinogenesis 2010, 31 (1), 71-82.

[21] Pewzner-Jung, Y.; Brenner, O.; Braun, S.; Laviad, E. L.; Ben-Dor, S.; Feldmesser, E.; Horn-Saban, S.; Amann-Zalcenstein, D.; Raanan, C.; Berkutzki, T.; Erez-Roman, R.; Ben-David, O.; Levy, M.; Holzman, D.; Park, H.; Nyska, A.; Merrill, A. H., Jr.; Futerman, A. H., A critical role for ceramide synthase 2 in liver homeostasis: II. insights into molecular changes leading to hepatopathy. J Biol Chem 2010, 285 (14), 10911-10923.

[22] Imgrund, S.; Hartmann, D.; Farwanah, H.; Eckhardt, M.; Sandhoff, R.; Degen, J.; Gieselmann, V.; Sandhoff, K.; Willecke, K., Adult ceramide synthase 2 (CERS2)deficient mice exhibit myelin sheath defects, cerebellar degeneration, and hepatocarcinomas. J Biol Chem 2009, 284 (48), 33549-33560.

[23] Holland, W. L.; Bikman, B. T.; Wang, L. P.; Yuguang, G.; Sargent, K. M.; Bulchand, S.; Knotts, T. A.; Shui, G.; Clegg, D. J.; Wenk, M. R.; Pagliassotti, M. J.; 
Scherer, P. E.; Summers, S. A., Lipid-induced insulin resistance mediated by the proinflammatory receptor TLR4 requires saturated fatty acid-induced ceramide biosynthesis in mice. J Clin Invest 2011, 121 (5), 1858-1870.

[24] Mari, M.; Fernandez-Checa, J. C., Sphingolipid signalling and liver diseases. Liver Int 2007, 27 (4), 440-450.

[25] Goggel, R.; Winoto-Morbach, S.; Vielhaber, G.; Imai, Y.; Lindner, K.; Brade, L.; Brade, H.; Ehlers, S.; Slutsky, A. S.; Schutze, S.; Gulbins, E.; Uhlig, S., PAFmediated pulmonary edema: a new role for acid sphingomyelinase and ceramide. Nat Med 2004, 10 (2), 155-160.

[26] Grassme, H.; Jendrossek, V.; Riehle, A.; von Kurthy, G.; Berger, J.; Schwarz, H.; Weller, M.; Kolesnick, R.; Gulbins, E., Host defense against Pseudomonas aeruginosa requires ceramide-rich membrane rafts. Nat Med 2003, 9 (3), 322-330.

[27] Garcia-Ruiz, C.; Colell, A.; Mari, M.; Morales, A.; Calvo, M.; Enrich, C.; Fernandez-Checa, J. C., Defective TNF-alpha-mediated hepatocellular apoptosis and liver damage in acidic sphingomyelinase knockout mice. J Clin Invest 2003, 111 (2), 197-208.

[28] Lang, P. A.; Schenck, M.; Nicolay, J. P.; Becker, J. U.; Kempe, D. S.; Lupescu, A.; Koka, S.; Eisele, K.; Klarl, B. A.; Rubben, H.; Schmid, K. W.; Mann, K.; Hildenbrand, S.; Hefter, H.; Huber, S. M.; Wieder, T.; Erhardt, A.; Haussinger, D.; Gulbins, E.; Lang, F., Liver cell death and anemia in Wilson disease involve acid sphingomyelinase and ceramide. Nat Med 2007, 13 (2), 164-170.

[29] Angulo, S.; Morales, A.; Danese, S.; Llacuna, L.; Masamunt, M. C.; Pultz, N.; Cifone, M. G.; De Simone, C.; Delgado, S.; Vila, J.; Panes, J.; Donskey, C.; FernandezCheca, J. C.; Fiocchi, C.; Sans, M., Probiotic sonicates selectively induce mucosal 
immune cells apoptosis through ceramide generation via neutral sphingomyelinase. PLoS One 2011, 6 (3), e16953.

[30] Coll, O.; Morales, A.; Fernandez-Checa, J. C.; Garcia-Ruiz, C., Neutral sphingomyelinase-induced ceramide triggers germinal vesicle breakdown and oxidantdependent apoptosis in Xenopus laevis oocytes. J Lipid Res 2007, 48 (9), 1924-1935.

[31] Mari, M.; Colell, A.; Morales, A.; Paneda, C.; Varela-Nieto, I.; Garcia-Ruiz, C.; Fernandez-Checa, J. C., Acidic sphingomyelinase downregulates the liver-specific methionine adenosyltransferase $1 \mathrm{~A}$, contributing to tumor necrosis factor-induced lethal hepatitis. J Clin Invest 2004, 113 (6), 895-904.

[32] Jenkins, R. W.; Idkowiak-Baldys, J.; Simbari, F.; Canals, D.; Roddy, P.; Riner, C. D.; Clarke, C. J.; Hannun, Y. A., A novel mechanism of lysosomal acid sphingomyelinase maturation: requirement for carboxyl-terminal proteolytic processing. J Biol Chem 2011, 286 (5), 3777-3788.

[33] Paris, F.; Grassme, H.; Cremesti, A.; Zager, J.; Fong, Y.; Haimovitz-Friedman, A.; Fuks, Z.; Gulbins, E.; Kolesnick, R., Natural ceramide reverses Fas resistance of acid sphingomyelinase(-/-) hepatocytes. J Biol Chem 2001, 276 (11), 8297-8305.

[34] Llacuna, L.; Mari, M.; Garcia-Ruiz, C.; Fernandez-Checa, J. C.; Morales, A., Critical role of acidic sphingomyelinase in murine hepatic ischemia-reperfusion injury. Hepatology 2006, 44 (3), 561-572.

[35] Deevska, G. M.; Rozenova, K. A.; Giltiay, N. V.; Chambers, M. A.; White, J.; Boyanovsky, B. B.; Wei, J.; Daugherty, A.; Smart, E. J.; Reid, M. B.; Merrill, A. H., Jr.; Nikolova-Karakashian, M., Acid Sphingomyelinase Deficiency Prevents Diet-induced Hepatic Triacylglycerol Accumulation and Hyperglycemia in Mice. J Biol Chem 2009, $284(13), 8359-8368$. 
[36] Vacaru, A. M.; Tafesse, F. G.; Ternes, P.; Kondylis, V.; Hermansson, M.; Brouwers, J. F.; Somerharju, P.; Rabouille, C.; Holthuis, J. C., Sphingomyelin synthaserelated protein SMSr controls ceramide homeostasis in the ER. J Cell Biol 2009, 185 (6), 1013-1027.

[37] Valaperta, R.; Chigorno, V.; Basso, L.; Prinetti, A.; Bresciani, R.; Preti, A.; Miyagi, T.; Sonnino, S., Plasma membrane production of ceramide from ganglioside GM3 in human fibroblasts. FASEB J 2006, 20 (8), 1227-1229.

[38] Caballero, F.; Fernandez, A.; Matias, N.; Martinez, L.; Fucho, R.; Elena, M.; Caballeria, J.; Morales, A.; Fernandez-Checa, J. C.; Garcia-Ruiz, C., Specific contribution of methionine and choline in nutritional nonalcoholic steatohepatitis: impact on mitochondrial S-adenosyl-L-methionine and glutathione. J Biol Chem 2010, 285 (24), 18528-18536.

[39] Susin, S. A.; Zamzami, N.; Castedo, M.; Daugas, E.; Wang, H. G.; Geley, S.; Fassy, F.; Reed, J. C.; Kroemer, G., The central executioner of apoptosis: multiple connections between protease activation and mitochondria in Fas/APO-1/CD95- and ceramide-induced apoptosis. $J$ Exp Med 1997, 186 (1), 25-37.

[40] Garcia-Ruiz, C.; Colell, A.; Mari, M.; Morales, A.; Fernandez-Checa, J. C., Direct effect of ceramide on the mitochondrial electron transport chain leads to generation of reactive oxygen species. Role of mitochondrial glutathione. J Biol Chem 1997, 272 (17), 11369-11377.

[41] Morales, A.; Paris, R.; Villanueva, A.; Llacuna, L.; Garcia-Ruiz, C.; FernandezCheca, J. C., Pharmacological inhibition or small interfering RNA targeting acid ceramidase sensitizes hepatoma cells to chemotherapy and reduces tumor growth in vivo. Oncogene 2007, 26 (6), 905-916. 
[42] Verheij, M.; Bose, R.; Lin, X. H.; Yao, B.; Jarvis, W. D.; Grant, S.; Birrer, M. J.; Szabo, E.; Zon, L. I.; Kyriakis, J. M.; Haimovitz-Friedman, A.; Fuks, Z.; Kolesnick, R. N., Requirement for ceramide-initiated SAPK/JNK signalling in stress-induced apoptosis. Nature 1996, 380 (6569), 75-79.

[43] Zundel, W.; Giaccia, A., Inhibition of the anti-apoptotic PI(3)K/Akt/Bad pathway by stress. Genes Dev 1998, 12 (13), 1941-1946.

[44] Mari, M.; Colell, A.; Morales, A.; Caballero, F.; Moles, A.; Fernandez, A.; Terrones, O.; Basanez, G.; Antonsson, B.; Garcia-Ruiz, C.; Fernandez-Checa, J. C., Mechanism of mitochondrial glutathione-dependent hepatocellular susceptibility to TNF despite NF-kappaB activation. Gastroenterology 2008, 134 (5), 1507-1520.

[45] Hassler, D. F.; Bell, R. M., Ceramidases: enzymology and metabolic roles. Adv Lipid Res 1993, 26, 49-57.

[46] Franzen, R.; Pautz, A.; Brautigam, L.; Geisslinger, G.; Pfeilschifter, J.; Huwiler, A., Interleukin-1beta induces chronic activation and de novo synthesis of neutral ceramidase in renal mesangial cells. J Biol Chem 2001, 276 (38), 35382-35389.

[47] Strelow, A.; Bernardo, K.; Adam-Klages, S.; Linke, T.; Sandhoff, K.; Kronke, M.; Adam, D., Overexpression of acid ceramidase protects from tumor necrosis factorinduced cell death. J Exp Med 2000, 192 (5), 601-612.

[48] Mahdy, A. E.; Cheng, J. C.; Li, J.; Elojeimy, S.; Meacham, W. D.; Turner, L. S.; Bai, A.; Gault, C. R.; McPherson, A. S.; Garcia, N.; Beckham, T. H.; Saad, A.; Bielawska, A.; Bielawski, J.; Hannun, Y. A.; Keane, T. E.; Taha, M. I.; Hammouda, H. M.; Norris, J. S.; Liu, X., Acid ceramidase upregulation in prostate cancer cells confers resistance to radiation: AC inhibition, a potential radiosensitizer. Mol Ther 2009, 17 (3), 430-438. 
[49] Selzner, M.; Bielawska, A.; Morse, M. A.; Rudiger, H. A.; Sindram, D.; Hannun, Y. A.; Clavien, P. A., Induction of apoptotic cell death and prevention of tumor growth by ceramide analogues in metastatic human colon cancer. Cancer Res 2001, 61 (3), 1233-1240.

[50] Gouaze-Andersson, V.; Flowers, M.; Karimi, R.; Fabrias, G.; Delgado, A.; Casas, J.; Cabot, M. C., Inhibition of acid ceramidase by a 2-substituted aminoethanol amide synergistically sensitizes prostate cancer cells to $\mathrm{N}$-(4-hydroxyphenyl) retinamide. Prostate 2011, 71 (10), 1064-1073.

[51] Bedia, C.; Casas, J.; Andrieu-Abadie, N.; Fabrias, G.; Levade, T., Acid ceramidase expression modulates the sensitivity of a375 melanoma cells to dacarbazine. J Biol Chem 2011, 286 (32), 28200-28209.

[52] Cuvillier, O.; Pirianov, G.; Kleuser, B.; Vanek, P. G.; Coso, O. A.; Gutkind, S.; Spiegel, S., Suppression of ceramide-mediated programmed cell death by sphingosine1-phosphate. Nature 1996, 381 (6585), 800-803.

[53] Perez, G. I.; Knudson, C. M.; Leykin, L.; Korsmeyer, S. J.; Tilly, J. L., Apoptosis-associated signaling pathways are required for chemotherapy-mediated female germ cell destruction. Nat Med 1997, 3 (11), 1228-1232.

[54] Pyne, N. J.; Pyne, S., Sphingosine 1-phosphate and cancer. Nat Rev Cancer 2010, 10 (7), 489-503.

[55] Visentin, B.; Vekich, J. A.; Sibbald, B. J.; Cavalli, A. L.; Moreno, K. M.; Matteo, R. G.; Garland, W. A.; Lu, Y.; Yu, S.; Hall, H. S.; Kundra, V.; Mills, G. B.; Sabbadini, R. A., Validation of an anti-sphingosine-1-phosphate antibody as a potential therapeutic in reducing growth, invasion, and angiogenesis in multiple tumor lineages. Cancer Cell 2006, 9 (3), 225-238. 
[56] Beljanski, V.; Lewis, C. S.; Smith, C. D., Antitumor activity of sphingosine kinase 2 inhibitor ABC294640 and sorafenib in hepatocellular carcinoma xenografts. Cancer Biol Ther 2011, 11 (5), 524-534.

[57] Gouaze, V.; Liu, Y. Y.; Prickett, C. S.; Yu, J. Y.; Giuliano, A. E.; Cabot, M. C., Glucosylceramide synthase blockade down-regulates P-glycoprotein and resensitizes multidrug-resistant breast cancer cells to anticancer drugs. Cancer Res 2005, 65 (9), $3861-3867$.

[58] Liu, Y. Y.; Patwardhan, G. A.; Bhinge, K.; Gupta, V.; Gu, X.; Jazwinski, S. M., Suppression of glucosylceramide synthase restores p53-dependent apoptosis in mutant p53 cancer cells. Cancer Res 2011, 71 (6), 2276-2285.

[59] Sun, Y.; Zhang, T.; Gao, P.; Meng, B.; Gao, Y.; Wang, X.; Zhang, J.; Wang, H.; Wu, X.; Zheng, W.; Zhou, G., Targeting glucosylceramide synthase downregulates expression of the multidrug resistance gene MDR1 and sensitizes breast carcinoma cells to anticancer drugs. Breast Cancer Res Treat 2010, 121 (3), 591-599.

[60] Gouaze-Andersson, V.; Cabot, M. C., Sphingolipid Metabolism and Drug Resistance In Hematological Malignancies. Anticancer Agents Med Chem 2011.

[61] di Bartolomeo, S.; Spinedi, A., Differential chemosensitizing effect of two glucosylceramide synthase inhibitors in hepatoma cells. Biochem Biophys Res Commun 2001, 288 (1), 269-274.

[62] Morales, A.; Colell, A.; Mari, M.; Garcia-Ruiz, C.; Fernandez-Checa, J. C., Glycosphingolipids and mitochondria: role in apoptosis and disease. Glycoconj $J \mathbf{2 0 0 4}$, $20(9), 579-588$.

[63] Merritt, W. D.; Morre, D. J.; Keenan, T. W., Gangliosides of liver tumors induced by $\mathrm{N}-2$-fluorenylacetamide. II. Alterations in biosynthetic enzymes. J Natl Cancer Inst 1978, 60 (6), 1329-1337. 
[64] Hakomori, S., Glycosylation defining cancer malignancy: new wine in an old bottle. Proc Natl Acad Sci U S A 2002, 99 (16), 10231-10233.

[65] McCaffery, M.; Yao, T. J.; Williams, L.; Livingston, P. O.; Houghton, A. N.; Chapman, P. B., Immunization of melanoma patients with BEC2 anti-idiotypic monoclonal antibody that mimics GD3 ganglioside: enhanced immunogenicity when combined with adjuvant. Clin Cancer Res 1996, 2 (4), 679-686.

[66] Chapman, P. B.; Wu, D.; Ragupathi, G.; Lu, S.; Williams, L.; Hwu, W. J.; Johnson, D.; Livingston, P. O., Sequential immunization of melanoma patients with GD3 ganglioside vaccine and anti-idiotypic monoclonal antibody that mimics GD3 ganglioside. Clin Cancer Res 2004, 10 (14), 4717-4723.

[67] Garcia-Ruiz, C.; Colell, A.; Morales, A.; Calvo, M.; Enrich, C.; FernandezCheca, J. C., Trafficking of ganglioside GD3 to mitochondria by tumor necrosis factoralpha. J Biol Chem 2002, 277 (39), 36443-36448.

[68] Lluis, J. M.; Buricchi, F.; Chiarugi, P.; Morales, A.; Fernandez-Checa, J. C., Dual role of mitochondrial reactive oxygen species in hypoxia signaling: activation of nuclear factor-\{kappa $\}$ B via c-SRC and oxidant-dependent cell death. Cancer Res 2007, 67 (15), 7368-7377.

[69] Lluis, J. M.; Llacuna, L.; von Montfort, C.; Barcena, C.; Enrich, C.; Morales, A.; Fernandez-Checa, J. C., GD3 synthase overexpression sensitizes hepatocarcinoma cells to hypoxia and reduces tumor growth by suppressing the cSrc/NF-kappaB survival pathway. PLoS One 2009, 4 (11), e8059.

[70] Colell, A.; Garcia-Ruiz, C.; Roman, J.; Ballesta, A.; Fernandez-Checa, J. C., Ganglioside GD3 enhances apoptosis by suppressing the nuclear factor-kappa Bdependent survival pathway. FASEB J 2001, 15 (6), 1068-1070. 
[71] Sa, G.; Das, T.; Moon, C.; Hilston, C. M.; Rayman, P. A.; Rini, B. I.; Tannenbaum, C. S.; Finke, J. H., GD3, an overexpressed tumor-derived ganglioside, mediates the apoptosis of activated but not resting T cells. Cancer Res 2009, 69 (7), 3095-3104.

[72] Kristal, B. S.; Brown, A. M., Apoptogenic ganglioside GD3 directly induces the mitochondrial permeability transition. J Biol Chem 1999, 274 (33), 23169-23175.

[73] Garcia-Ruiz, C.; Colell, A.; Paris, R.; Fernandez-Checa, J. C., Direct interaction of GD3 ganglioside with mitochondria generates reactive oxygen species followed by mitochondrial permeability transition, cytochrome c release, and caspase activation. FASEB J 2000, 14 (7), 847-858.

[74] Paris, R.; Morales, A.; Coll, O.; Sanchez-Reyes, A.; Garcia-Ruiz, C.; FernandezCheca, J. C., Ganglioside GD3 sensitizes human hepatoma cells to cancer therapy. $J$ Biol Chem 2002, 277 (51), 49870-49876.

[75] Sorice, M.; Garofalo, T.; Misasi, R.; Manganelli, V.; Vona, R.; Malorni, W., Ganglioside GD3 as a RAFT Component in Cell Death Regulation. Anticancer Agents Med Chem 2011.

[76] Stover, T.; Kester, M., Liposomal delivery enhances short-chain ceramideinduced apoptosis of breast cancer cells. J Pharmacol Exp Ther 2003, 307 (2), 468-475. [77] Shabbits, J. A.; Mayer, L. D., Intracellular delivery of ceramide lipids via liposomes enhances apoptosis in vitro. Biochim Biophys Acta 2003, 1612 (1), 98-106.

[78] Stover, T. C.; Sharma, A.; Robertson, G. P.; Kester, M., Systemic delivery of liposomal short-chain ceramide limits solid tumor growth in murine models of breast adenocarcinoma. Clin Cancer Res 2005, 11 (9), 3465-3474.

[79] Tagaram, H. R.; Divittore, N. A.; Barth, B. M.; Kaiser, J. M.; Avella, D.; Kimchi, E. T.; Jiang, Y.; Isom, H. C.; Kester, M.; Staveley-O'Carroll, K. F., 
Nanoliposomal ceramide prevents in vivo growth of hepatocellular carcinoma. Gut 2011, 60 (5), 695-701.

[80] Tran, M. A.; Smith, C. D.; Kester, M.; Robertson, G. P., Combining nanoliposomal ceramide with sorafenib synergistically inhibits melanoma and breast cancer cell survival to decrease tumor development. Clin Cancer Res 2008, 14 (11), $3571-3581$.

[81] Bielawski, J.; Pierce, J. S.; Snider, J.; Rembiesa, B.; Szulc, Z. M.; Bielawska, A., Comprehensive quantitative analysis of bioactive sphingolipids by high-performance liquid chromatography-tandem mass spectrometry. Methods Mol Biol 2009, 579, 443467.

[82] Shaner, R. L.; Allegood, J. C.; Park, H.; Wang, E.; Kelly, S.; Haynes, C. A.; Sullards, M. C.; Merrill, A. H., Jr., Quantitative analysis of sphingolipids for lipidomics using triple quadrupole and quadrupole linear ion trap mass spectrometers. $J$ Lipid Res 2009, 50 (8), 1692-1707.

[83] Merrill, A. H., Jr.; Stokes, T. H.; Momin, A.; Park, H.; Portz, B. J.; Kelly, S.; Wang, E.; Sullards, M. C.; Wang, M. D., Sphingolipidomics: a valuable tool for understanding the roles of sphingolipids in biology and disease. J Lipid Res 2009, 50 Suppl, S97-102.

[84] Hammad, S. M.; Pierce, J. S.; Soodavar, F.; Smith, K. J.; Al Gadban, M. M.; Rembiesa, B.; Klein, R. L.; Hannun, Y. A.; Bielawski, J.; Bielawska, A., Blood sphingolipidomics in healthy humans: impact of sample collection methodology. J Lipid Res 2010, 51 (10), 3074-3087.

[85] Maxfield, F. R.; Tabas, I., Role of cholesterol and lipid organization in disease. Nature 2005, 438 (7068), 612-621. 
[86] van Meer, G.; Voelker, D. R.; Feigenson, G. W., Membrane lipids: where they are and how they behave. Nat Rev Mol Cell Biol 2008, 9 (2), 112-124.

[87] Gulati, S.; Liu, Y.; Munkacsi, A. B.; Wilcox, L.; Sturley, S. L., Sterols and sphingolipids: dynamic duo or partners in crime? Prog Lipid Res 2010, 49 (4), 353-365. [88] Brown, A. J.; Sun, L.; Feramisco, J. D.; Brown, M. S.; Goldstein, J. L., Cholesterol addition to ER membranes alters conformation of SCAP, the SREBP escort protein that regulates cholesterol metabolism. Mol Cell 2002, 10 (2), 237-245.

[89] Brown, M. S.; Goldstein, J. L., Multivalent feedback regulation of HMG CoA reductase, a control mechanism coordinating isoprenoid synthesis and cell growth. $J$ Lipid Res 1980, 21 (5), 505-517.

[90] Goldstein, J. L.; Brown, M. S., Regulation of the mevalonate pathway. Nature 1990, 343 (6257), 425-430.

[91] Horton, J. D.; Goldstein, J. L.; Brown, M. S., SREBPs: activators of the complete program of cholesterol and fatty acid synthesis in the liver. J Clin Invest $\mathbf{2 0 0 2}$, $109(9), 1125-1131$.

[92] Garcia-Ruiz, C.; Mari, M.; Colell, A.; Morales, A.; Caballero, F.; Montero, J.; Terrones, O.; Basanez, G.; Fernandez-Checa, J. C., Mitochondrial cholesterol in health and disease. Histol Histopathol 2009, 24 (1), 117-132.

[93] Van Rooyen, D. M.; Larter, C. Z.; Haigh, W. G.; Yeh, M. M.; Ioannou, G.; Kuver, R.; Lee, S. P.; Teoh, N. C.; Farrell, G. C., Hepatic Free Cholesterol Accumulates in Obese, Diabetic Mice and Causes Nonalcoholic Steatohepatitis. Gastroenterology 2011.

[94] Caballero, F.; Fernandez, A.; De Lacy, A. M.; Fernandez-Checa, J. C.; Caballeria, J.; Garcia-Ruiz, C., Enhanced free cholesterol, SREBP-2 and StAR expression in human NASH. J Hepatol 2009, 50 (4), 789-796. 
[95] Miller, W. L., Steroidogenic acute regulatory protein (StAR), a novel mitochondrial cholesterol transporter. Biochim Biophys Acta 2007, 1771 (6), 663-676.

[96] Soccio, R. E.; Breslow, J. L., StAR-related lipid transfer (START) proteins: mediators of intracellular lipid metabolism. J Biol Chem 2003, 278 (25), 22183-22186.

[97] Soccio, R. E.; Breslow, J. L., Intracellular cholesterol transport. Arterioscler Thromb Vasc Biol 2004, 24 (7), 1150-1160.

[98] Li, W. P.; Liu, P.; Pilcher, B. K.; Anderson, R. G., Cell-specific targeting of caveolin-1 to caveolae, secretory vesicles, cytoplasm or mitochondria. J Cell Sci 2001, 114 (Pt 7), 1397-1408.

[99] Mastrodonato, M.; Calamita, G.; Rossi, R.; Mentino, D.; Bonfrate, L.; Portincasa, P.; Ferri, D.; Liquori, G. E., Altered distribution of caveolin-1 in early liver steatosis. Eur J Clin Invest 2011, 41 (6), 642-651.

[100] Bosch, M.; Mari, M.; Herms, A.; Fernandez, A.; Fajardo, A.; Kassan, A.; Giralt, A.; Colell, A.; Balgoma, D.; Barbero, E.; Gonzalez-Moreno, E.; Matias, N.; Tebar, F.; Balsinde, J.; Camps, M.; Enrich, C.; Gross, S. P.; Garcia-Ruiz, C.; Perez-Navarro, E.; Fernandez-Checa, J. C.; Pol, A., Caveolin-1 deficiency causes cholesterol-dependent mitochondrial dysfunction and apoptotic susceptibility. Curr Biol 2011, 21 (8), 681686.

[101] Sano, R.; Annunziata, I.; Patterson, A.; Moshiach, S.; Gomero, E.; Opferman, J.; Forte, M.; d'Azzo, A., GM1-ganglioside accumulation at the mitochondria-associated ER membranes links ER stress to $\mathrm{Ca}(2+)$-dependent mitochondrial apoptosis. Mol Cell 2009, $36(3), 500-511$.

[102] Fernandez, A.; Llacuna, L.; Fernandez-Checa, J. C.; Colell, A., Mitochondrial cholesterol loading exacerbates amyloid beta peptide-induced inflammation and neurotoxicity. J Neurosci 2009, 29 (20), 6394-6405. 
[103] Mari, M.; Caballero, F.; Colell, A.; Morales, A.; Caballeria, J.; Fernandez, A.; Enrich, C.; Fernandez-Checa, J. C.; Garcia-Ruiz, C., Mitochondrial free cholesterol loading sensitizes to TNF- and Fas-mediated steatohepatitis. Cell Metab 2006, 4 (3), 185-198.

[104] Llacuna, L.; Fernandez, A.; Montfort, C. V.; Matias, N.; Martinez, L.; Caballero, F.; Rimola, A.; Elena, M.; Morales, A.; Fernandez-Checa, J. C.; Garcia-Ruiz, C., Targeting cholesterol at different levels in the mevalonate pathway protects fatty liver against ischemia-reperfusion injury. J Hepatol 2011, 54 (5), 1002-1010.

[105] Hall, E. A.; Ren, S.; Hylemon, P. B.; Rodriguez-Agudo, D.; Redford, K.; Marques, D.; Kang, D.; Gil, G.; Pandak, W. M., Detection of the steroidogenic acute regulatory protein, StAR, in human liver cells. Biochim Biophys Acta 2005, 1733 (2-3), 111-119.

[106] Sever, N.; Yang, T.; Brown, M. S.; Goldstein, J. L.; DeBose-Boyd, R. A., Accelerated degradation of HMG CoA reductase mediated by binding of insig- 1 to its sterol-sensing domain. Mol Cell 2003, 11 (1), 25-33.

[107] Song, B. L.; Sever, N.; DeBose-Boyd, R. A., Gp78, a membrane-anchored ubiquitin ligase, associates with Insig-1 and couples sterol-regulated ubiquitination to degradation of HMG CoA reductase. Mol Cell 2005, 19 (6), 829-840.

[108] Nguyen, A. D.; McDonald, J. G.; Bruick, R. K.; DeBose-Boyd, R. A., Hypoxia stimulates degradation of 3-hydroxy-3-methylglutaryl-coenzyme A reductase through accumulation of lanosterol and hypoxia-inducible factor-mediated induction of insigs. $J$ Biol Chem 2007, 282 (37), 27436-27446.

[109] Siperstein, M. D., Cholesterol, cholesterogenesis and cancer. Adv Exp Med Biol 1995, 369, 155-166. 
[110] Feo, F.; Canuto, R. A.; Bertone, G.; Garcea, R.; Pani, P., Cholesterol and phospholipid composition of mitochondria and microsomes isolated from morris hepatoma 5123 and rat liver. FEBS Lett 1973, 33 (2), 229-232.

[111] Colell, A.; Garcia-Ruiz, C.; Lluis, J. M.; Coll, O.; Mari, M.; Fernandez-Checa, J. C., Cholesterol impairs the adenine nucleotide translocator-mediated mitochondrial permeability transition through altered membrane fluidity. J Biol Chem 2003, 278 (36), 33928-33935.

[112] Montero, J.; Morales, A.; Llacuna, L.; Lluis, J. M.; Terrones, O.; Basanez, G.; Antonsson, B.; Prieto, J.; Garcia-Ruiz, C.; Colell, A.; Fernandez-Checa, J. C., Mitochondrial cholesterol contributes to chemotherapy resistance in hepatocellular carcinoma. Cancer Res 2008, 68 (13), 5246-5256.

[113] Crain, R. C.; Clark, R. W.; Harvey, B. E., Role of lipid transfer proteins in the abnormal lipid content of Morris hepatoma mitochondria and microsomes. Cancer Res 1983, 43 (7), 3197-3202.

[114] Campbell, A. M.; Capuano, A.; Chan, S. H., A cholesterol-binding and transporting protein from rat liver mitochondria. Biochim Biophys Acta 2002, 1567 (12), 123-132.

[115] Feo, F.; Canuto, R. A.; Garcea, R.; Gabriel, L., Effect of cholesterol content on some physical and functional properties of mitochondria isolated from adult rat liver, fetal liver, cholesterol-enriched liver and hepatomas AH-130, 3924A and 5123. Biochim Biophys Acta 1975, 413 (1), 116-134.

[116] Lucken-Ardjomande, S.; Montessuit, S.; Martinou, J. C., Bax activation and stress-induced apoptosis delayed by the accumulation of cholesterol in mitochondrial membranes. Cell Death Differ 2008, 15 (3), 484-493. 
[117] Demierre, M. F.; Higgins, P. D.; Gruber, S. B.; Hawk, E.; Lippman, S. M., Statins and cancer prevention. Nat Rev Cancer 2005, 5 (12), 930-942.

[118] Garcia-Ruiz, C.; Mari, M.; Colell, A.; Morales, A.; Fernandez-Checa, J. C., Metabolic Therapy: Lessons from Liver Diseases. Curr Pharm Des 2011. 
Figure 1

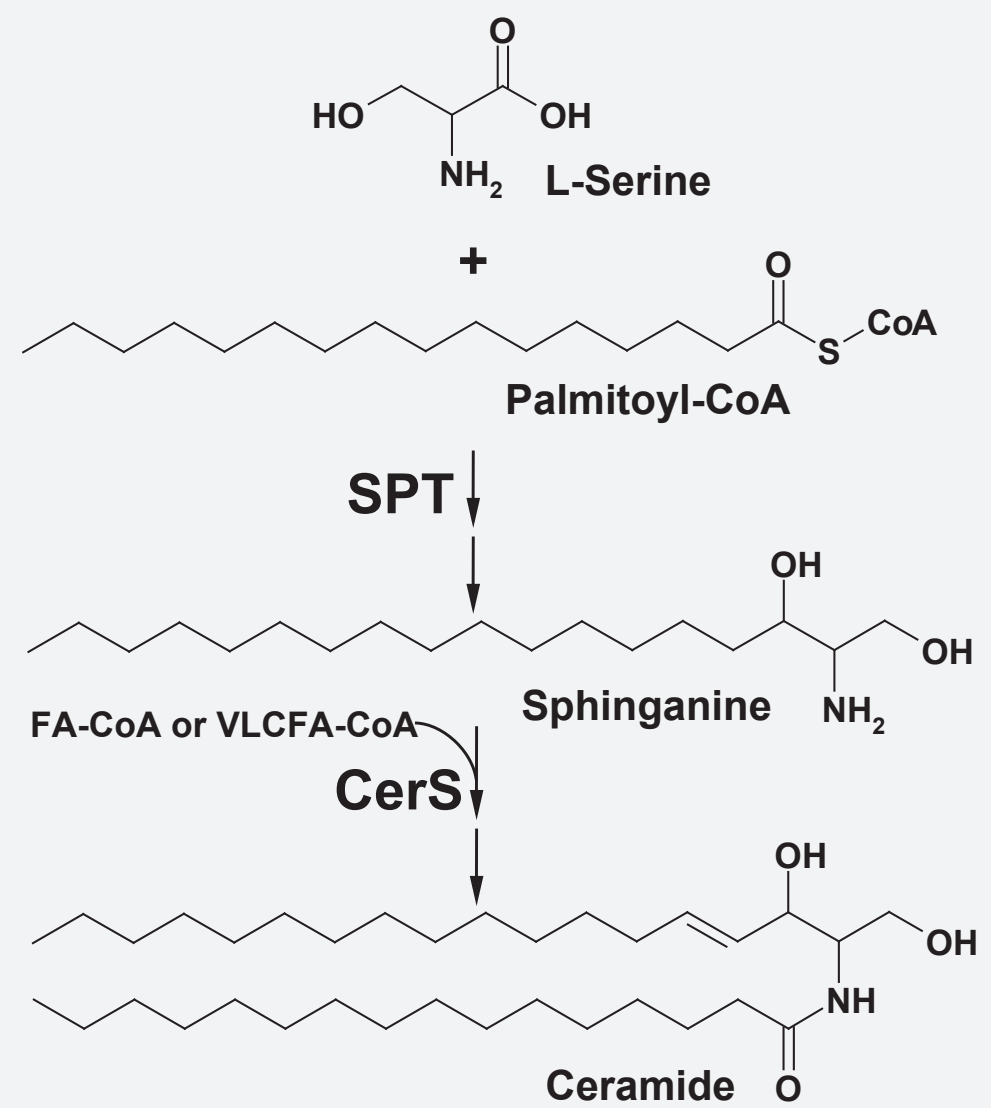




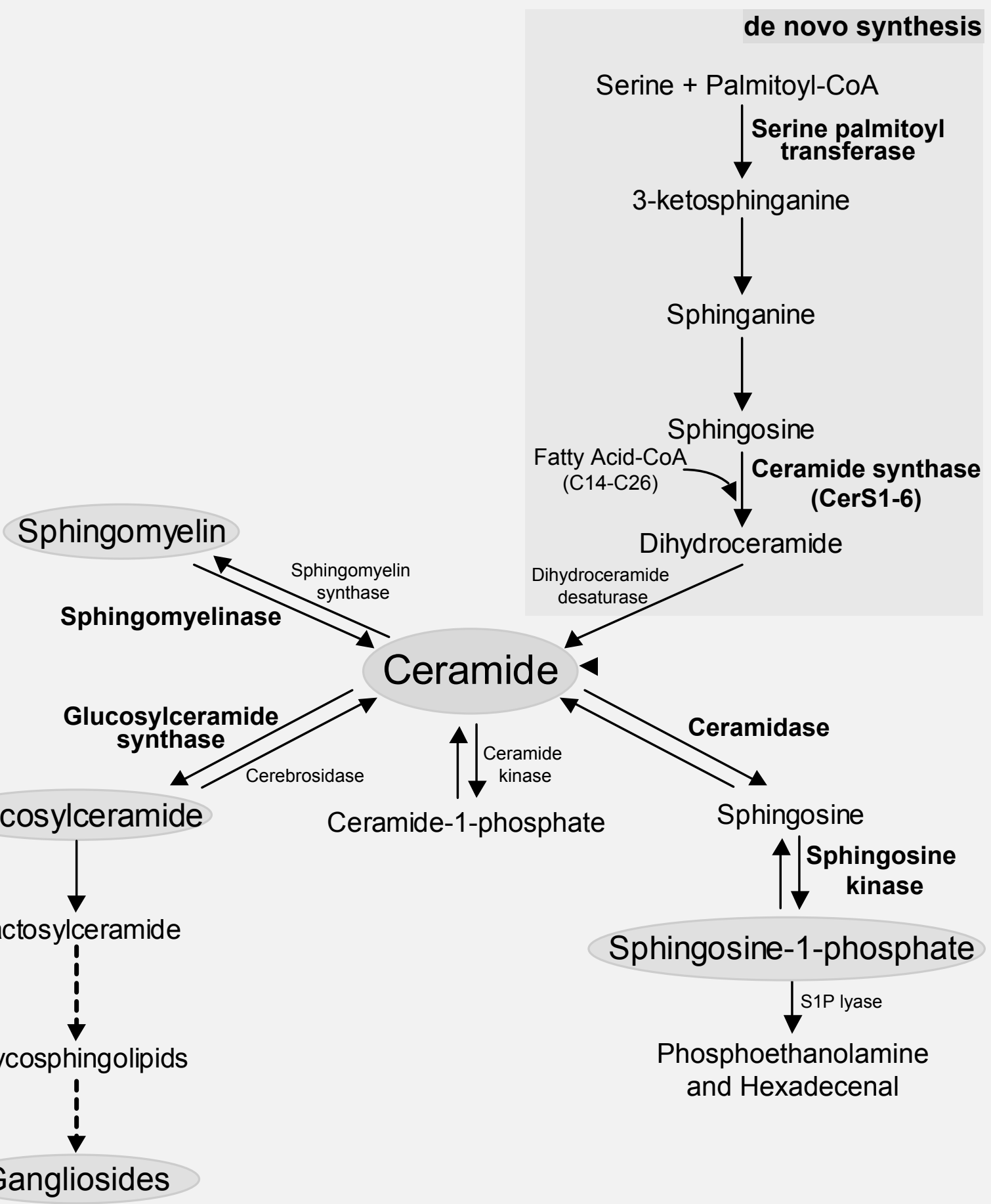


Figure 3

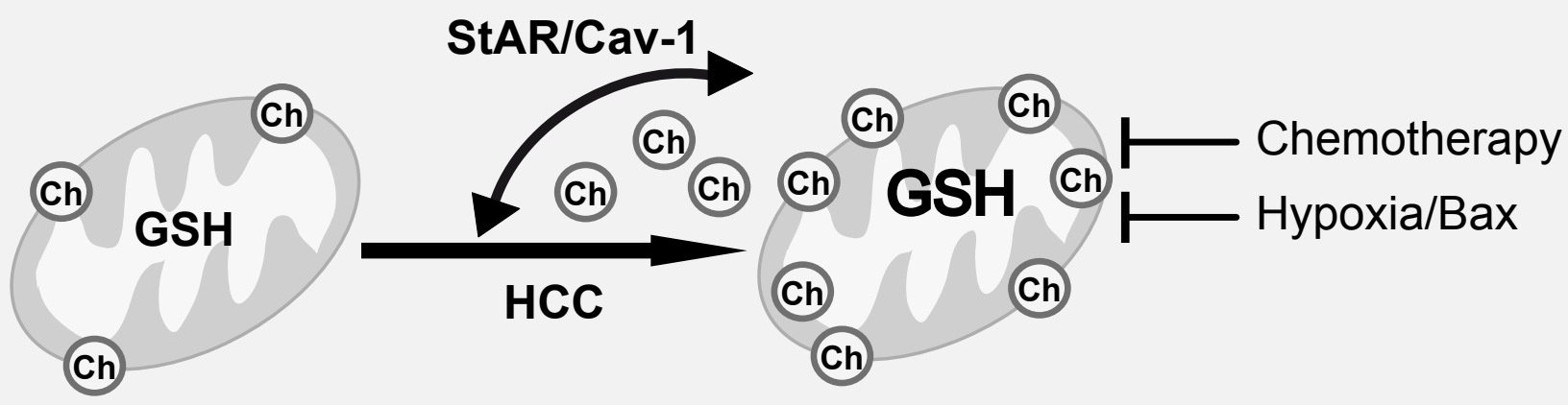

NASH/ASH

Steatosis $\mathrm{HCC}$

time 
Figure 4
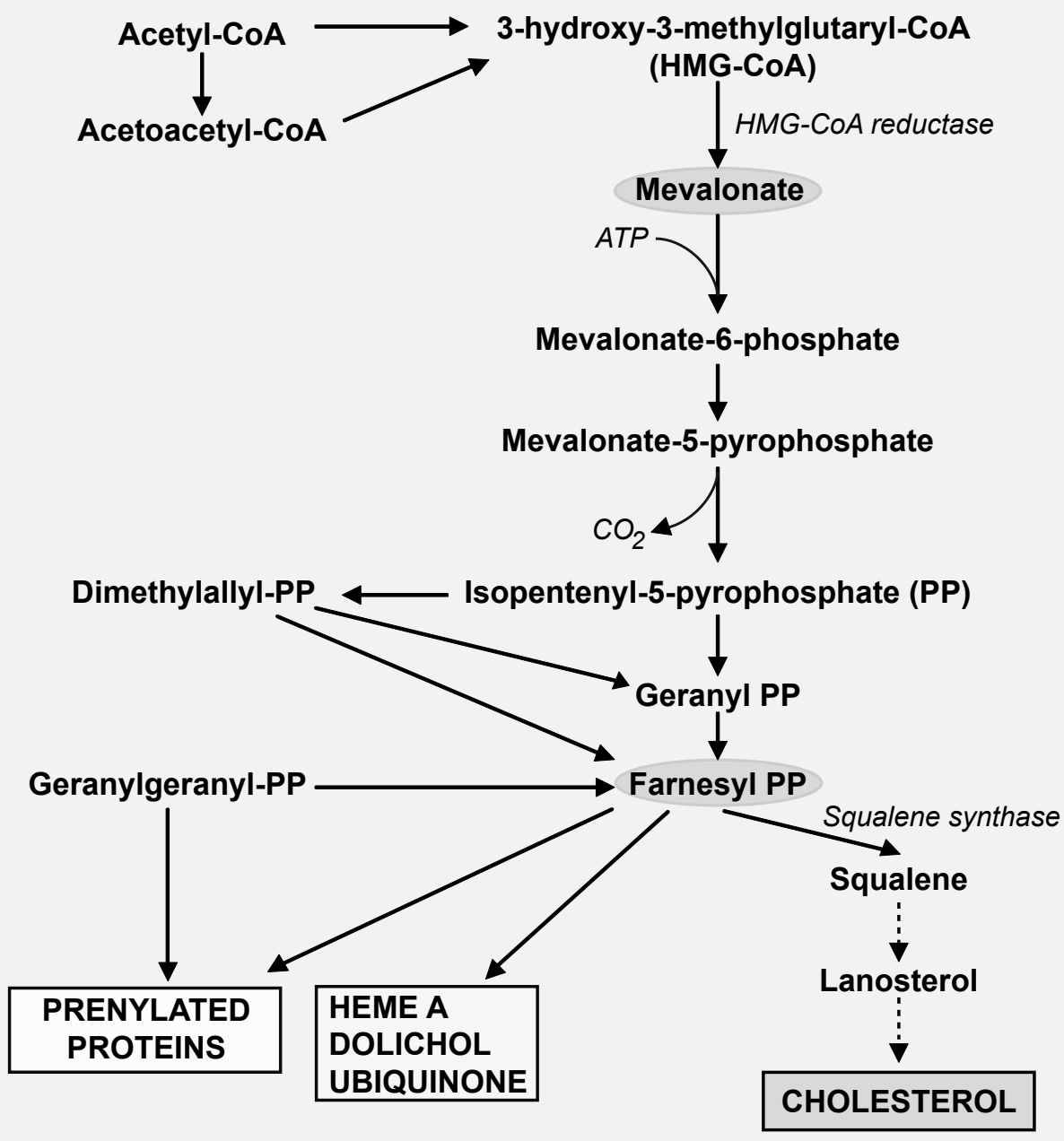